\title{
Consuming Foods and Household Products in Greece: A Statistical Analysis
}

\section{Persefoni Polychronidou ${ }^{1}$ Ioannis Petasakis $^{2}$ Giannoula Florou ${ }^{3}$ Anastasios Karasavvoglou ${ }^{4}$}

\begin{abstract}
:
The total income of the Greek households has been decreased in the last years. So, purchases are bravely decreased. In this paper, we study the consuming of household products and basic foods by the Greek households. We wish to study if consuming behaviour of Greek households has been changed after the crisis; if the consumers check the prices of the products more carefully; if they prefer more economic labels, etc. For this purpose, an empirical analysis with a questionnaire has been conducted in February 2014 in Greece. We present and analyze the responses of this questionnaire, using descriptive statistics and Data Analysis methods.
\end{abstract}

Key Words: Consuming Behavior, Household Products and Food, Statistical Analysis, Factor Analysis

JEL Classification: D12

\footnotetext{
1 Adjoined Assistant Professor, Accountancy and Finance Department, Eastern Macedonia and Thrace Institute of Technology, Agios Loucas, 65404, Kavala, Greece, polychr@teiemt.gr

2 Adjoined Assistant Professor, Accountancy and Finance Department, Eastern Macedonia and Thrace Institute of Technology , Agios Loucas, 65404, Kavala, Greece

3 Professor, Accountancy and Finance Department, Eastern Macedonia and Thrace Institute of Technology , Agios Loucas, 65404, Kavala, Greece

4 Professor, Accountancy and Finance Department, Eastern Macedonia and Thrace Institute of Technology,Agios Loucas, 65404, Kavala, Greece
} 


\section{Introduction}

The economic crisis of these past years has affected all aspects of consumption. The financial status if individuals (wages, refund of capitals, etc.) has changed and in most cases has decreased. As a consequence, consumers are adjusting their consumer behaviour to the new financial situation by reducing the consuming expenditures and re-define their consumer prototype. Nowadays, Greeks are very "tight" in consuming foods and products. An important question is how daily consuming habits, like consuming milk, oil, bred, etc. have changed.

During these years, several researchers study the relation between age, gender and economical status with the consumer behaviour (Hoyer et al. 2012; Lingyte et al. 2011; Polychronidou et al., 2011; Thalassinos et al. 2012). Economic crisis is forcing many consumers all around the world to re-evaluate their consuming needs and behaviour (Consumer Bahaviour Report 2009; 2010; 2011; De Mooij 2004; Cornia 1994; McKenzie 2006; Kang and Sawada 2008; McKenzie, Schargrodsky 2010); in Greece as well (Hellenic Statistical Authority 2010; 2011; 2012; 2013; 2014; Athanassopoulos, Labroukos 1999; Matsaganis 2011).

Specifically, in Greece, the Consumer Price Index (CPI) in June 2014 compared with June 2013 decreased by $1.1 \%$, and the CPI in June 2013 compared with June 2012, decreased by $0.4 \%$ (Hellenic Statistical Authority, 2013; 2014). The decrease of the CPI in June 2014 was mostly due to the change in $3.0 \%$ of the group "Food and nonalcoholic beverages", mainly due to a reduction in the price of fresh vegetables, fresh fruits, fresh potatoes, fresh fish, cereals and preparations, meat in general, sugar and mineral water and soft drinks-juices. In individual products.

The aim of this paper is to study with an empirical analysis if consuming behaviour of Greek households has been changed after the crisis. Taking into account the respondents age, marital status, area of residence, education, occupation and annual income, we study whether their consumer habits have changed regarding expensive foods (meat, olive oil, etc.), fruit and vegetables, basic provisions (bred, flour, etc.). Also, we study the consumers' attitude regarding price versus quality, if they prefer private label products and make their own price-research before buying. Finally, we study whether consumers are affected by advertizing. The research methodology is indicated in the following section. In section three results of the statistical analysis are presented and in the last section, the conclusions of the paper are quoted.

\section{Methodology}

The study was conducted in Greece in February 2014 by the Department of Accountancy and Finance of the Eastern Macedonia and Thrace Institute of Technology. The data were collected using a structured questionnaire containing 12 
questions. The questionnaires were distributed randomly to cosnumers. They were asked to complete the questionnaires anonymously and return them. The questions were divided into two sections. First section consisted of seven questions related to demographic data and section 2 consisted of five questions regarding consuming habits in specific products, four of these question were multiple ones. The questions were mainly of closed type, meaning the consumers had to choose from specific answers. The collected data were analysed using descriptive statistics and the program SPSS v19.

\section{Results}

\subsection{Descriptive Statistics}

The sample size is 488 with mean age 35.74 years (95\% confidence interval ( 34.53 , 36.96)). The minimum age is 18 and the maximum 76 (see Table 1).

\section{Table 1. Sample Age}

\begin{tabular}{|l|l|l|}
\hline Genter & Frequency & Percent \\
\hline Male & 176 & 36.1 \\
\hline Female & 302 & 61.9 \\
\hline Missing & 10 & 2.0 \\
\hline Total & 488 & 100.0 \\
\hline
\end{tabular}

The area of residence of our sample is shown in Table 2. The majority leaves in urban areas. Almost half (48.6\%) are married, 39.8\% are unmarried and the rest are divorced or widowers.

Table 2. Area of Residence

\begin{tabular}{|c|c|c|}
\hline Area of residence & Frequency & Percent \\
\hline Rural area & 121 & 24.8 \\
\hline Suburban areas & 82 & 16.8 \\
\hline Urban areas & 271 & 55.5 \\
\hline Missing & 14 & 2.9 \\
\hline Total & 488 & 100.0 \\
\hline
\end{tabular}


The majority of our sample are educated (45.1\%), 34.2\% have secondary education, $9.4 \%$ have primary educated and $8 \%$ hold a master or doctorate degree. The occupation of our sample is shown in Table 3.

Table 3. Occupation

\begin{tabular}{|c|c|c|}
\hline Occupation & Frequency & Percent \\
\hline Unemployed & 68 & 13,9 \\
\hline Public servant & 71 & 14,5 \\
\hline Freelance & 69 & 14,1 \\
\hline Private Employee & 86 & 17,6 \\
\hline Retired & 29 & 5,9 \\
\hline Student & 99 & 20.3 \\
\hline Other & 54 & 11,1 \\
\hline Missing & 12 & 2,5 \\
\hline Total & 488 & 100.0 \\
\hline
\end{tabular}

The majority of our sample has low annual income, with the majority (51.8\%) to earn less than 15.000 euro per year (see Table 4).

Table 4. Annual Income

\begin{tabular}{|c|c|c|}
\hline Annual Income & Frequency & Percent \\
\hline Less than 5.000€ & 83 & 17,0 \\
\hline $5.001 €-10.000 €$ & 80 & 16,4 \\
\hline $10.001 €-15.000 €$ & 90 & 18,4 \\
\hline $15.001 €-20.000 €$ & 64 & 13,1 \\
\hline $20.001 €-25.000 €$ & 45 & 9,2 \\
\hline $25.001 €-30.000 €$ & 39 & 8,0 \\
\hline
\end{tabular}




\begin{tabular}{|c|c|c|}
\hline $30.001 €-35.000 €$ & 26 & 5,3 \\
\hline $35.001 €-40.000 €$ & 9 & 1,8 \\
\hline $40.001 €-45.000 €$ & 5 & 1,0 \\
\hline More than $45.001 €$ & 14 & 2,9 \\
\hline Missing & 33 & 6,8 \\
\hline Total & 488 & 100.0 \\
\hline
\end{tabular}

\subsection{Variation in Consumer Habits as to the Kind of Consuming Foods}

The questionnaire contained a set of items regarding changes in consumption of 11 food products as to their frequency of buying. These questions are in a 5-point Likert scale ( $1=$ Strongly disagree to $5=$ Strongly agree). We carried out Factor Analysis to see if consumer behaviour is similar for certain food products. The KMO value is 0.818, the Bartlett's Test of Sphericity value is 1866.7, while the corresponding p-value is less than 0.001. Factor analysis returned 3 factors, as presented in Table 5. Subsequently we use the Cronbach Alpha index to test the reliability of the factors.

Table 5. Factor Analysis for Food Products

\begin{tabular}{|c|c|c|}
\hline Factor 1: Expensive Foods & & Cronbach's Alpha \\
\hline Ollive oil & 0.601 & \multirow{5}{*}{0.818} \\
\hline Dairy & 0.530 & \\
\hline Red meat & 0.854 & \\
\hline Chicken & 0.763 & \\
\hline Fish & 0.653 & \\
\hline Factor 2: Fruit \& Vegetables & & Cronbach's Alpha \\
\hline Vegetables & 0.825 & \multirow{2}{*}{0.828} \\
\hline Fruit & 0.851 & \\
\hline
\end{tabular}


International Journal of Economics \& Business Administration, I(2)2014

104 P. Polychronidou-I. Petrakis - G. Florou - A. Karasavvoglou

\begin{tabular}{|c|c|c|}
\hline Factor 3: Basic provisions & & Cronbach's Alpha \\
\hline flour & 0.547 & \\
\hline Legumes & 0.701 & \multirow{2}{*}{0.706} \\
\hline Pasta & 0.791 & \\
\hline Bread & 0.674 & \\
\hline
\end{tabular}

We observe that all index values are higher than 0.7 , indicating satisfactory consistency and reliable factors. So, we created three new variables, one for each factor. The values of each new variable are the mean value of the individual items that consist each factor.

Table 6. Mean Value for Each Factor

\begin{tabular}{|l|l|l|l|}
\hline \multicolumn{2}{|c|}{} & \multicolumn{2}{l|}{$95 \%$ Confidence Interval for Mean } \\
\hline Factors & Mean & Lower Bound & Upper Bound \\
\hline Factor 1: Expensive Foods & 2,68 & 2,62 & 2,74 \\
\hline Factor 2: Fruit-Vegetables & 3,07 & 3.00 & 3,14 \\
\hline Factor 3: Basic Provisions & 3,12 & 3,07 & 3,18 \\
\hline
\end{tabular}

A mean value close to 3 indicates neither increase nor decrease of the frequency of consumption of the specific products, while values above 3 means increase and below 3 means decrease, compared to the period before the financial crisis. So, Fruit-Vegetables and basic provisions seem to show an increase, while Expensive Foods show a decrease in consumption. Furthermore, we study whether there is a relationship between the above factors and demographic characteristics. Factor 3 (Basic Provisions) is correlated with the area of residence. We use Analysis Of Variance with Tukey correction for multiple comparisons ( $\mathrm{F}$-test $=4.2, \mathrm{df}=448$, $\mathrm{p}$ value $=0.16$ ). The mean value of the third factor for each different area of residence is presented in Table 7.

Table 7. Mean Value of Factor 3 in Correlation with Area of Residence

\begin{tabular}{|c|c|c|c|c|}
\hline $\begin{array}{c}\text { Factor 3: Basic } \\
\text { provisions }\end{array}$ & \multirow{2}{*}{$\mathrm{N}$} & \multirow{2}{*}{ Mean } & \multicolumn{2}{|c|}{ 95\% Confidence Interval for Mean } \\
\cline { 4 - 5 } & & & Lower Bound & Upper Bound \\
\hline Rural area & 115 & 3,26 & 3,15 & 3,37 \\
\hline Suburban areas & 77 & 3,12 & 2,98 & 3,25 \\
\hline Urban areas & 259 & 3,06 & 2,99 & 3,14 \\
\hline Total & 451 & 3,12 & 3,07 & 3,18 \\
\hline
\end{tabular}


We conclude that in all three areas the consumption of basic provisions seems to increases. Moreover, the 95\% Confidence Interval for the mean difference of factor 3 between rural and urban areas is $(0.0372,0.3572)$, which means that the consumption of basic provisions from respondents of rural areas has increased more than those from urban areas $(p$-value $=0.011$ ). In Figure 1 the allocation of factor 3 between the three areas of residence is shown.

Figure 1. The allocation of factor 3 between the three areas of residence

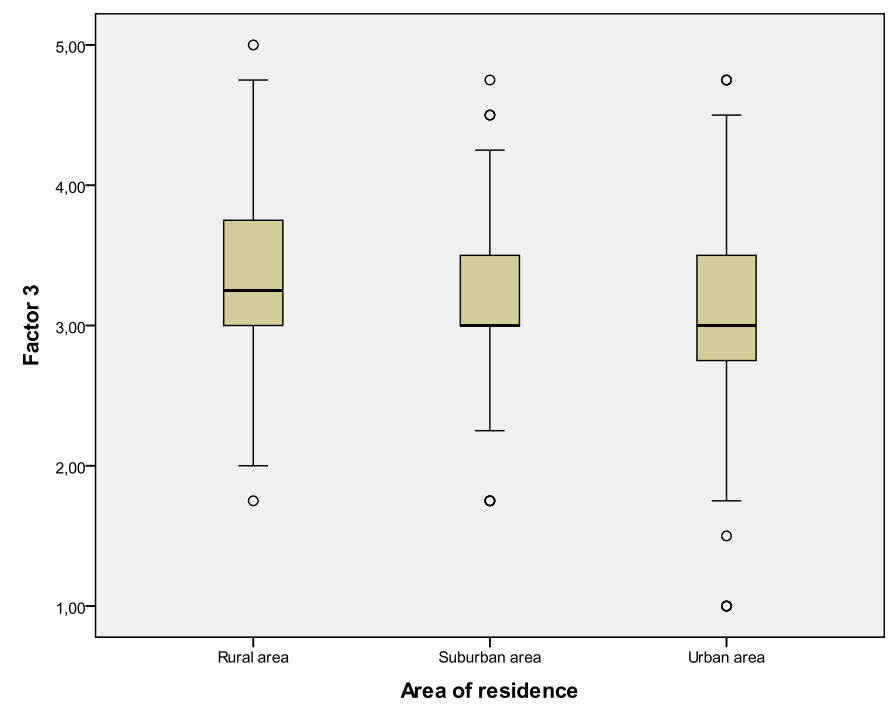

Statistical analysis did not reveal further correlations between these 3 factors and other demographic data.

\subsection{Consumer Behavior in General}

The questionnaire contained a set of 12 items regarding changes in consumer behavior. We carried out Factor Analysis to see if we can create some group of items according to consumer behavior. The KMO value is 0.837 , the Bartlett's Test of Sphericity value is 2015,3 while the corresponding p-value is less than 0.001 . Factor analysis returned 3 factors as presented in Table 8. Subsequently we use the Cronbach Alpha index to test the reliability of factors. 
Table 8. Factor Analysis

\begin{tabular}{|c|c|c|}
\hline Factor 1 Price over quality & & $\begin{array}{l}\text { Cronbach's } \\
\text { Alpha }\end{array}$ \\
\hline Prefer cheaper label in foods & 0.524 & \multirow{5}{*}{0.837} \\
\hline Prefer cheaper label in cosmetics (shampoo, toothpaste,... & 0.509 & \\
\hline Try to replace first need products with more cheaper & 0.551 & \\
\hline Affected by the price and not the quality of foods & 0.825 & \\
\hline Affected by the price and not the quality of household products & 0.822 & \\
\hline Affected by the price and not the quality of cosmetics & 0.791 & \\
\hline Factor 2 - Organizing purchase & & $\begin{array}{c}\text { Cronbach's } \\
\text { Alpha }\end{array}$ \\
\hline Do research before buying & 0.791 & \multirow{3}{*}{0.745} \\
\hline Make a list & 0.778 & \\
\hline Prefer cheaper label in household products (cleaning, ... ) & 0.626 & \\
\hline Factor 3 - Private Label Products & & $\begin{array}{c}\text { Cronbach's } \\
\text { Alpha }\end{array}$ \\
\hline Prefer them in food products & 0.758 & \multirow{3}{*}{0.732} \\
\hline Prefer them in household products & 0.828 & \\
\hline Prefer them in cosmetics products & 0.760 & \\
\hline
\end{tabular}

We observe that all index values are higher than 0.7 indicating satisfactory consistency and reliable factors. So, we created three new variables, one for each factor. The values of each new variable are the mean value of the individual items which consist each factor. 
Table 9. Mean Value for Each Factor

\begin{tabular}{|c|c|c|c|}
\hline & & \multicolumn{2}{|c|}{ 95\% Confidence Interval for Mean } \\
\hline Mean value for each one factor & Mean & Lower Bound & Upper Bound \\
\hline Factor 1 - Price over quality & 3.18 & 3.11 & 3.26 \\
\hline Factor 2- Organizing purchase & 3.90 & 3.83 & 3.96 \\
\hline Factor 3- Private Label Products & 2.55 & 2.48 & 2.63 \\
\hline
\end{tabular}

As it is shown in the above table, consumer purchases are now affected more by price than quality and are made after organizing (market research, shopping list, etc.), compared with the period before the financial crisis. It is remarkable that the preference of private label products seems to have reduced. In addition, we checked whether the above factors differ in their demographic characteristics. Using the t-test for independent samples we found $(\mathrm{p}$-value $=0.018, \mathrm{t}=-2.381, \mathrm{df}=450)$ that women are affected more than the price of the products instead to their quality, to a greater extent than men. The average of factor "Price over quality", separately for men and women is given in table 10 .

Table 10. Gender and Price Over Quality and Organizing Purchase

\begin{tabular}{|c|c|c|c|c|}
\hline & Gender & $\mathrm{N}$ & Mean & Std. Deviation \\
\hline \multirow{2}{*}{ Price over quality } & Male & 164 & 3.06 & 0.79 \\
\cline { 2 - 5 } & Female & 288 & 3.25 & 0.81 \\
\hline \multirow{2}{*}{ Organizing purchase } & Male & 171 & 3.67 & 0.74 \\
\cline { 2 - 5 } & Female & 297 & 4.03 & 0.68 \\
\hline
\end{tabular}

We also checked if factor 'Organizing purchase' differs over gender. Both women and men denote that they organize their purchases more than the period before the crisis. However, women seem to be more organized than men ( $\mathrm{p}$-value $<0.001, \mathrm{t}=-$ $5.231, \mathrm{df}=466,95 \%$ Confidence Interval of the Difference $(-0.48,-0.22))$.

\subsection{How Consumers are Affected by Advertising}

Finally, the questionnaire contained a set of 7 items regarding the relation between consumption and advertisement. These questions are in a 5-point Likert scale ( $1=$ Strongly disagree to $5=$ Strongly agree). We carried out Factor Analysis to see if we can create some group of items. The KMO value is 0.789 , the Bartlett's Test of Sphericity value is 1232.7 while the corresponding p-value is less than 0.001 . Factor analysis returned 2 factors as presented in Table 11 . Subsequently we use the Cronbach Alpha index to test the reliability of the factors. 
Table 11. Consuming and Advertisements

\begin{tabular}{|c|c|c|}
\hline Advertising via classic way & & \multirow{2}{*}{ Cronbach's Alpha } \\
\hline TV & 0.810 & \multirow{2}{*}{0.801} \\
\hline Radio & 0.654 & \\
\hline Brochure & 0.836 & \\
\hline Magazines & 0.699 & \\
\hline \hline Advertising via new technologies & & \multirow{2}{*}{ Cronbach's Alpha } \\
\hline Internet & 0.810 & \multirow{2}{*}{0.782} \\
\hline Social media & 0.654 & \\
\hline Telephone - sms & 0.836 & \\
\hline
\end{tabular}

We observe that all index values are higher than 0.7 , indicating satisfactory consistency and reliable factors. So, we created two new variables, one for each factor. The values of each new variable are the mean value of the individual items which consists each factor. Using the t-test for independent samples we found (pvalue $=0.035, \mathrm{t}=-2.1, \mathrm{df}=448$ ) that women are affected more than men by advertising via classic way. Advertising via new technologies does not depend by gender ( $\mathrm{p}$-value $=0.857, \mathrm{t}=0.18, \mathrm{df}=452$ ). The average of factors 'Advertising via classic way' and 'Advertising via new technologies is indicated separately for men and women in the following table.

Table 12. Gender and Average of Advertising

\begin{tabular}{|c|c|c|c|c|}
\hline & Gender & $\mathrm{N}$ & Mean & $\begin{array}{c}\text { Std. } \\
\text { Deviation }\end{array}$ \\
\hline \multirow{2}{*}{ Advertising via classic way } & Male & 170 & 2.82 & .90 \\
\cline { 2 - 5 } & Female & 286 & 3.00 & .85 \\
\hline \multirow{2}{*}{ Advertising via new technologies } & Male & 168 & 2.62 & .93 \\
\cline { 2 - 5 } & Female & 286 & 2.61 & .99 \\
\hline
\end{tabular}


Using Spearman correlation we found that age is not correlated with the way that consumers are affected by classic advertising (Person correlation coefficient $=0.034$, p-value $=0.472$ ), but is negatively correlated with the way that consumers are affected by advertising via new technologies (Person correlation coefficient = 0.308 , p-value $<0,001)$. That is, the older the consumer is, the smallest influenced he or she is by new technologies advertising. Finally, we studied whether advertising is correlated with the area of residence. In Table 13 it is shown that the different ways of advertising do not differ in relation with residence (ANOVA F-test=2.51, pvalue $=0.082$ ). The effect of Advertising via new technologies is higher in urban areas compared with rural area (ANOVA F-test $=4.62, \mathrm{p}$-value $=0.01$, Tukey p-value for mean difference $=0.11,95 \%$ Confidence Interval $(-0.57,-0.60))$.

\section{Table 13. Mean Value of Factor 'Advertising via Classic Way'}

\begin{tabular}{|c|c|c|c|c|}
\hline $\begin{array}{c}\text { Advertising via classic } \\
\text { way }\end{array}$ & \multirow{2}{*}{$\mathrm{N}$} & \multirow{2}{*}{ Mean } & \multicolumn{2}{|c|}{ 95\% Confidence Interval for Mean } \\
\cline { 4 - 5 } & & & Lower Bound & Upper Bound \\
\hline Rural area & 116 & 2,94 & 2,76 & 3,11 \\
\hline Suburban areas & 80 & 3,11 & 2.94 & 3,29 \\
\hline Urban areas & 256 & 2,87 & 2,76 & 2,97 \\
\hline $\begin{array}{c}\text { Advertising via new } \\
\text { technologies }\end{array}$ & & & & \\
\hline Rural area & 114 & 2,37 & 2,19 & 2,55 \\
\hline Suburban areas & 80 & 2,69 & 2,51 & 2,88 \\
\hline Urban areas & 256 & 2,68 & 2,56 & 2,81 \\
\hline
\end{tabular}

\section{Conclusion}

The results of the empirical analysis are in compliance with the reality in Greece. Consumer habits of Greeks have changed regarding expensive foods, fruit and vegetables and basic provisions. Fruit-Vegetables and basic provisions seem to show an increase in the frequency of consumption, while Expensive Foods show a decrease in consumption, as it was expected. Regarding the correlation of these food categories-factors with the demographic data, only basic provisions are correlated with the area of residence. As it is shown from our analysis, consumer purchases are affected more by price than quality of products and are made after organizing of consumers (market research, shopping list, etc.), However, consumers do not prefer private label products, which are usually cheaper than the other ones. Regarding correlation with gender, it is shown that women are affected more than men from the price of the products instead to their quality. As to effect of advertizing, women are affected more than men by advertising via classic way, while advertising via new 
International Journal of Economics \& Business Administration, I(2)2014

technologies does not correlate with gender. Also, age is negatively correlated with the way that consumers are affected by advertising via new technologies.

\section{References}

Antreas D. Athanassopoulos, Nikos S. Labroukos, "Corporate customer behaviour towards financial services: empirical results from the emerging market of Greece," International Journal of Bank Marketing, Vol. 17, No. 6:274-285, 1999.

Consumer Behavior Report, "Economic Trends in Consumer Spending," available at https://mr.pricegrabber.com/Economic_Trends_in_Consumer_Spending_June_2009_C BR_1.pdf (21/3/2013), 2009.

Consumer Behavior Report, "US Shopping Behavior in this Economic Climate," available at https://mr.pricegrabber.com/US_Shopping_Behavior_in_this_Economic_Climate.pdf (21/3/2013), 2010.

Consumer Behavior Report, "Back-to-School Shopping Behavior," available at https://mr.pricegrabber.com/Back_to_School_Shopping_Behavior_CBR_2011.pdf (21/3/2013), 2011.

Cornia, G.A., "Poverty, food consumption, and nutrition during the transition to the market economy in Eastern Europe," American Economic Review, Vol. 84, No. 2:297-302, 1994.

De Mooij, M., Consumer Behavior and Culture. Thousand Oaks, CA, Sage, 2004.

Hellenic Statistical Authority, "Consumer Price Index (CPI) - National Index”, 2010.

Hellenic Statistical Authority, "Consumer Price Index (CPI) - National Index”, 2011.

Hellenic Statistical Authority, "Consumer Price Index (CPI) - National Index”, 2012.

Hellenic Statistical Authority, "Consumer Price Index (CPI) - National Index”, 2013.

Hellenic Statistical Authority, "Consumer Price Index (CPI) - National Index”, 2014.

Manos Matsaganis, "The welfare state and the crisis: the case of Greece," Journal of European Social Policy, Vol. 21, No. 5:501-512, 2011.

McKenzie, D., "The consumer response to the Mexican Peso crisis," Economic Development and Cultural Change, Vol. 55, No. 1:139-72, 2006.

David McKenzie, Ernesto Schargrodsky, "Buying less, but shopping more: the use of nonmarket labor during a crisis," BREAD Working Paper, No. 92, 2010.

Monika Lingyte, Stavros Valsamidis, Nikolaos Mitsinis and Persefoni Polychronidou, "ECommerce Behaviour of Lithuanian and Greek women," Intellectual Economics, Vol. 1, No. 9:85-98, 2011.

Persefoni Polychronidou, Stavros Valsamidis, Giannoula Florou, Anastasios Karasavvoglou, "Comparison of e-commerce behaviour among women consumers of Balkan and Baltic regions," Scientific Bulletin-Economic Sciences, Vol. 10, No. 2:11-23, 2011.

Sung Jin Kang and Yasuyuki Sawada, "Credit crunch and household welfare, the case of the Korean financial crisis," The Japanese Economic Review, Vol. 59, No. 4:438-458, 2008.

Thalassinos I. E., Maditinos D. and Paschalidis A. (2012), "Observing Evidence of Insider Trading in the Athens Stock Exchange (ASE)", Journal of Economic Structures, 1:8, 52-67, 03 Dec. http://www.journalofeconomicstructures.com/content/1/1/8

Wayne D. Hoyer, Deborah J. MacInnis, Rik Pieters, Consumer Behavior, South-Western College Pub., $6^{\text {th }}$ edition, USA, 2012. 